\title{
Patient radiation exposure during transforaminal lumbar endoscopic spine surgery: a prospective study
}

\author{
Menno Iprenburg, MD, ${ }^{1}$ Ralf Wagner, MD, ${ }^{2}$ Alexander Godschalx, MD, ${ }^{1}$ and \\ Albert E. Telfeian, MD, $\mathrm{PhD}^{3}$ \\ ${ }^{1}$ Spine Clinic Iprenburg, Veenhuizen, The Netherlands; 'Ligamenta Spine Centre, Frankfurt am Main, Germany; and ${ }^{3}$ Department \\ of Neurosurgery, Rhode Island Hospital, The Warren Alpert Medical School of Brown University, Providence, Rhode Island
}

\begin{abstract}
OBJECTIVE The aim of this study was to describe patient radiation exposure during single-level transforaminal endoscopic lumbar discectomy procedures at levels L2-5 and L5-S1.

METHODS Radiation exposure was monitored in 151 consecutive patients undergoing single-level transforaminal endoscopic lumbar discectomy procedures. Two groups were studied: patients undergoing procedures at the L4-5 level or above and those undergoing an L5-S1 procedure.

RESULTS For the discectomy procedures at L4-5 and above, the average duration of fluoroscopy was 38.4 seconds and the mean calculated patient radiation exposure dose was $1.5 \mathrm{mSv}$. For the L5-S1 procedures, average fluoroscopy time was 54.6 seconds and the mean calculated radiation exposure dose was $2.1 \mathrm{mSv}$. The average patient radiation exposure dose among these cases represents a 3.5-fold decrease compared with the senior surgeon's first 100 cases.

CONCLUSIONS Transforaminal lumbar endoscopic discectomy can be used as a minimally invasive technique for the treatment of lumbar radiculopathy in the setting of a herniated lumbar disc without the significant concern of exposing the patient to harmful doses of radiation. One caveat is that both the surgeon and the patient are likely to be exposed to higher doses of radiation during a surgeon's early experience in minimally invasive endoscopic spine surgery.

http://thejns.org/doi/abs/10.3171/2015.11.FOCUS15485
\end{abstract}

KEY WORDS endoscopic discectomy; minimally invasive; transforaminal; radiation

$\mathrm{T}$ RANSFORAMINAL endoscopic lumbar discectomy is a minimally invasive spinal surgery that was introduced by Kambin and Gellman in 1973. ${ }^{9}$ Advances in endoscopic visualization and instrumentation, as well as increased patient demand for more minimally invasive procedures, has heightened the popularity of the technique, particularly outside of the United States. Like other minimally invasive spine procedures, whether needle based (vertebroplasty, kyphoplasty, injections, and rhizotomy) or performed through a tubular retractor system (minimally invasive discectomies, interbody fusions, and screw placement), endoscopic spine surgery depends heavily on the use of fluoroscopy for targeting and instrument placement.

Here we describe our experience treating patients with herniated lumbar discs, who presented with persistent lumbar radiculopathy despite conservative nonoperative treatment, using transforaminal endoscopic discectomy. A prospective study of radiation exposure is presented for 2 groups of patients: those treated with lumbar disc herniations at L4-5 and above, and those treated with L5-S1 disc herniations. The patient groups are separated to account for the possibility that navigating over the iliac crest to access the L5-S1 foramen may lead to increased patient exposure to radiation.

\section{Methods \\ Participants}

One hundred fifty-one consecutive patients undergoing transforaminal lumbar endoscopic discectomy procedures at L2-3, L3-4, L4-5, and L5-S1 performed by the senior surgeon at a single institution were included in this prospective study. Data are presented only for patients who 
underwent single-level, unilateral endoscopic decompressions - no cases of multilevel or bilateral decompressions or decompressions adjacent to a fusion were included in the study. The data represent a multiinstitutional collaboration to examine the outcomes of transforaminal endoscopic spine surgery.

Patients were selected for treatment based on the results of their MRI, physical examination, and dermatomal pain pattern. All patients considered for endoscopic surgical treatment had already exhausted more conservative treatments, which included but were not limited to physical therapy and epidural steroid injections.

\section{Operative Technique}

Patients were positioned in the lateral decubitus position with the operating room table reversed, the patient's flank over the break in the table, and a rolled blanket under the patient just superior to the iliac crest. The procedure was done under local analgesia and intravenous sedation; the level of anesthetic was titrated so the patient was able to communicate with the surgeon throughout the procedure. The joimax TESSYS endoscopic system was used for the procedure. Percutaneous entry was established entering through the skin 8-14 cm lateral to the midline. Using intermittent fluoroscopic guidance, alternating between lateral and anteroposterior views, we advanced a $25-\mathrm{cm}$ 18-gauge needle and placed it in the disc space through Kambin's triangle, between the exiting and traversing nerves. An anteroposterior fluoroscopic view was used to ensure that the disc space was entered before the needle was past the middle of the pedicle. Sequential reamers were used to enlarge the neural foramen by removing the ventral aspect of the superior facet. By rotating the beveled cannula working channel and endoscope, $360^{\circ}$ visualization of the annulus and the exiting and traversing nerve roots was possible. After adequate discectomy and prior to terminating the procedure, the patient was asked the status of his or her radicular symptoms at rest and during leg movement. The working channel and scope were removed, pressure was held on the 5-mm incision for 5 minutes, and the wound was closed with a single interrupted suture.

\section{Data Collection}

For each patient a thermoluminescent whole-body dosimeter (Panasonic) was placed at the midline just superior to the superior gluteal fold (Fig. 1). The dosimeters were stored in a radiation-free space between the procedures and read by the Dutch National Dose Registration and Information System. The dosimeters for the 151 consecutive patients were collected for an 8-month period. The millisievert $(\mathrm{mSv})$ radiation dose calculated is the derived unit of ionizing radiation in the International System of Units and is a measure of the health effect of low levels of ionizing radiation on the human body. The radiation doses expressed in this study are calculated and derived by taking the monthly total doses from the dosimeters collected and dividing them by the fluoroscopy times.

The SPSS version $14.0 \mathrm{~K}$ software (SPSS Inc.) was used to calculate t-tests. A p value $<0.05$ was considered statistically significant.

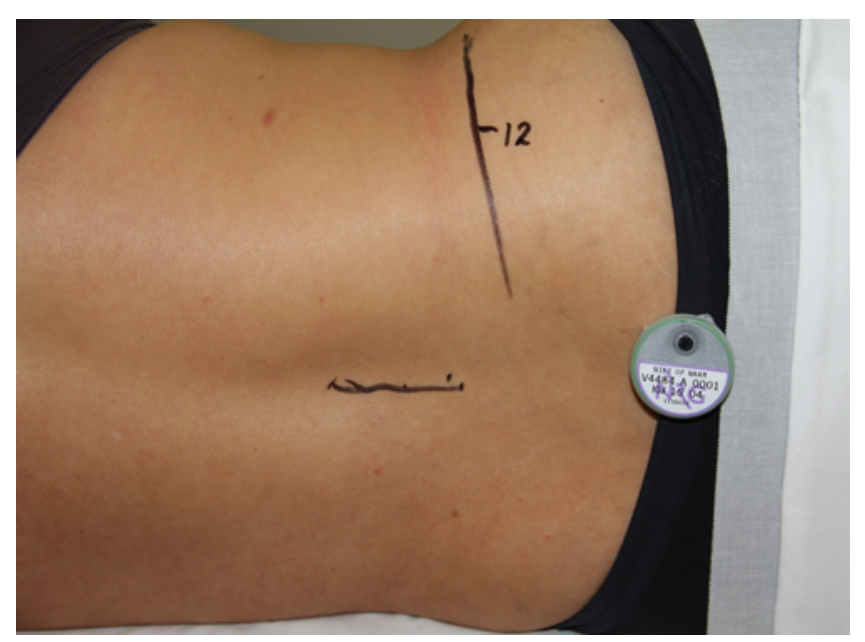

FIG. 1. Patient positioned in the lateral decubitus position (in this photograph, the head is to the left) with the flank over a break in the table. The thermoluminescent dosimeter is positioned at the midline just over the superior gluteal fold.

\section{Results}

Among the 151 consecutive patients who underwent single-level endoscopic discectomy, 3 were treated at $\mathrm{L} 2-3,18$ at $\mathrm{L} 3-4,72$ at L4-5, and 58 at L5-S1 (Table 1). Surveys at 6 weeks postsurgery indicated that $95 \%$ of patients were very satisfied, $5 \%$ were moderately satisfied, and $0 \%$ were not satisfied with their surgery. There were no reports of infection, dural tear, thrombophlebitis, spinal instability, or renal, vascular, or pulmonary injury. There were no serious complications such as cauda equina syndrome or nerve damage resulting in paralysis. Note that previously reported complications have included infection, dysesthesia, thrombophlebitis, dural tear, vascular injury, and death. ${ }^{21}$

The radiation exposure doses and procedure times for lumbar levels L4-5 and above and L5-S1 are presented in Table 1. The mean duration of fluoroscopy for levels L4-5 and above and the mean patient radiation exposure dose during these procedures were 38.4 seconds and $1.5 \mathrm{mSv}$, respectively. The mean fluoroscopy time for L5-S1 and the mean radiation exposure dose during this procedure were 54.6 seconds and $2.1 \mathrm{mSv}$, respectively. The 2 groups showed a statistically significant difference in fluoroscopy time and radiation exposure $(\mathrm{p}<0.05$, $\mathrm{t}$-test). The senior surgeon has performed over 2150 transforaminal endoscopic discectomies. The average fluoroscopy time for his

TABLE 1. Patient data for fluoroscopy times and radiation dose by lumbar level treated

\begin{tabular}{cccc}
\hline Lumbar Level & $\begin{array}{c}\text { No. of } \\
\text { Patients }\end{array}$ & $\begin{array}{c}\text { Mean Duration of } \\
\text { Fluoroscopy }(\mathrm{sec})^{*}\end{array}$ & $\begin{array}{c}\text { Mean Radiation } \\
\text { Dose }(\mathrm{mSv})^{*}\end{array}$ \\
\hline L2-3 & 3 & $46.0 \pm 13.9$ & $1.8 \pm 0.5$ \\
\hline L3-4 & 18 & $33.0 \pm 5.9$ & $1.3 \pm 0.2$ \\
\hline L4-5 & 72 & $39.4 \pm 12.7$ & $1.5 \pm 0.5$ \\
\hline L2-3, L3-4, \& L4-5 & 93 & $38.4 \pm 11.9$ & $1.5 \pm 0.5$ \\
\hline L5-S1 & 58 & $54.6 \pm 24.7$ & $2.1 \pm 1.0$ \\
\hline
\end{tabular}

* Values are expressed as the means \pm standard deviations. 
first 100 single-level lumbar cases was 158 seconds-approximately 3.5 times the average fluoroscopy time calculated here.

\section{Discussion}

Minimally invasive spine surgery and needle-based interventional spine procedures typically depend on ionizing radiation for localization and guidance in placing instrumentation. Other studies have addressed spine surgeons' radiation exposure in minimally invasive spine surgeries ${ }^{2,3,5,7,8,10,12,14,15,18,20,22}$ and in endoscopic spine surgery. ${ }^{1}$ Here we prospectively looked at the exposure of patients to radiation during endoscopic spine surgery. Several interesting conclusions can be drawn from the data collected.

First, the radiation exposure to patients during transforaminal endoscopic spine surgery is small and in the range of 1-2 mSv. To put that into perspective, the published estimates for cosmic radiation doses to fulltime airline crewmembers is about $2 \mathrm{mSv}$ per year. ${ }^{11,17}$ The average American is exposed to about $6 \mathrm{mSv}$ of radiation annually, according to the National Council on Radiation Protection and Measurements. ${ }^{16}$ Half of this typically comes from background radiation that occurs naturally in the environment, and half comes from medical tests such as radiographs, mammograms, and CT scans. ${ }^{16}$

Second, L5-S1 procedures, on average, take longer than procedures performed at L4 -5 and above and thus result in more patient exposure to radiation. If radiation exposure is an issue for a patient and could impact his or her decision to pursue endoscopic versus nonendoscopic surgery, then it is important to disclose that L5-S1 discectomy procedures require more fluoroscopy exposure.

Third, the fluoroscopy times demonstrated here are about 3.5 times less than those reported in the Ahn et al. study on surgeon radiation exposure in endoscopic spine surgery and 3.5 times less than the fluoroscopy times for the senior surgeon's first 100 endoscopic discectomy cases. ${ }^{1}$ Authors of other studies have discussed the surgeon's learning curve in endoscopic spine surgery and its impact on patient outcomes; less experience implementing the endoscopic surgical technique will probably result in longer fluoroscopy times, another factor that may affect radiation exposure to the patient and surgeon. ${ }^{23}$

The data presented here are intended to provide for the first time information on patient radiation exposure during endoscopic lumbar discectomy procedures. The measured radiation doses presented are actually calculated doses determined by pooling patient dosimeter readings and then dividing the mean radiation dose by the fluoroscopy time $(\mathrm{mSv} / \mathrm{sec})$. The radiation exposure doses to patients are in actuality not just dependent on the duration of fluoroscopy but on other factors as well. Estimates could be improved by recording the average kilovolt peak and tube current (milliamperage) for the patient. Even these estimates are subject to considerable error as real endoscopic spine procedures are often complex and require dynamic changes in field size, geometry, position, and kilovolt peak.,4,6,13,19 Radiation exposure doses also depend on a number of factors intrinsic to the fluoroscopy machine, the body composition of the patient, and the user setup, such as collimation and source-to-skin distance. ${ }^{4,6,13,19}$ And although the data on patient radiation exposure during endoscopic lumbar discectomy procedures presented here represent calculated approximations, we conclude that 1) patient radiation exposure during endoscopic spine surgery is small, 2) L5-S1 discectomies are significantly longer in duration than discectomies at other lumbar levels and require longer fluoroscopy times, and 3) the surgeon learning curve involved in endoscopic spine procedures also has an impact on patient radiation exposure. This represents important information for patients who are considering pursuing endoscopic surgical treatment for a herniated lumbar disc.

\section{Conclusions}

In summary, like other minimally invasive and needlebased interventional spine procedures, endoscopic lumbar discectomy requires patient radiation exposure through fluoroscopy, but these doses are small and probably not enough to discourage patients from considering endoscopic spine surgery for the reason of increased radiation exposure.

\section{References}

1. Ahn Y, Kim CH, Lee JH, Lee SH, Kim JS: Radiation exposure to the surgeon during percutaneous endoscopic lumbar discectomy: a prospective study. Spine (Phila Pa 1976) 38:617-625, 2013

2. Bindal RK, Glaze S, Ognoskie M, Tunner V, Malone R, Ghosh S: Surgeon and patient radiation exposure in minimally invasive transforaminal lumbar interbody fusion. J Neurosurg Spine 9:570-573, 2008

3. Fitousi NT, Efstathopoulos EP, Delis HB, Kottou S, Kelekis AD, Panayiotakis GS: Patient and staff dosimetry in vertebroplasty. Spine (Phila Pa 1976) 31:E884-E890, 2006

4. Geise RA, O'Dea TJ: Radiation dose in interventional fluoroscopic procedures. Appl Radiat Isot 50:173-184, 1999

5. Harstall R, Heini PF, Mini RL, Orler R: Radiation exposure to the surgeon during fluoroscopically assisted percutaneous vertebroplasty: a prospective study. Spine (Phila Pa 1976) 30:1893-1898, 2005

6. Heyd RL, Kopecky KK, Sherman S, Lehman GA, Stockberger SM: Radiation exposure to patients and personnel during interventional ERCP at a teaching institution. Gastrointest Endosc 44:287-292, 1996

7. Jones DP, Robertson PA, Lunt B, Jackson SA: Radiation exposure during fluoroscopically assisted pedicle screw insertion in the lumbar spine. Spine (Phila Pa 1976) 25:15381541,2000

8. Kallmes DF, O E, Roy SS, Piccolo RG, Marx WF, Lee JK, et al: Radiation dose to the operator during vertebroplasty: prospective comparison of the use of 1-cc syringes versus an injection device. AJNR Am J Neuroradiol 24:1257-1260, 2003

9. Kambin P, Gellman PH: Percutaneous lateral discectomy of the lumbar spine: a preliminary report. Clin Orthop Relat Res (174): 127-132, 1983

10. Kim CW, Lee YP, Taylor W, Oygar A, Kim WK: Use of navigation-assisted fluoroscopy to decrease radiation exposure during minimally invasive spine surgery. Spine J 8:584-590, 2008

11. Kojo K, Helminen M, Leuthold G, Aspholm R, Auvinen A: Estimating the cosmic radiation dose for a cabin crew with flight timetables. J Occup Environ Med 49:540-545, 2007

12. Kruger R, Faciszewski T: Radiation dose reduction to medical staff during vertebroplasty: a review of techniques and 
methods to mitigate occupational dose. Spine (Phila Pa 1976) 28:1608-1613, 2003

13. Leibovic SJ, Caldicott WJ: Gastrointestinal fluoroscopy: patient dose and methods for its reduction. Br J Radiol 56:715-719, 1983

14. Mariscalco MW, Yamashita T, Steinmetz MP, Krishnaney AA, Lieberman IH, Mroz TE: Radiation exposure to the surgeon during open lumbar microdiscectomy and minimally invasive microdiscectomy: a prospective, controlled trial. Spine (Phila Pa 1976) 36:255-260, 2011

15. Mroz TE, Yamashita T, Davros WJ, Lieberman IH: Radiation exposure to the surgeon and the patient during kyphoplasty. J Spinal Disord Tech 21:96-100, 2008

16. National Council on Radiation Protection \& Measurements: NCRP Report No. 91. Recommendation on Limits for Exposure of Ionizing Radiation. Bethesda, MD: National Council on Radiation Protection \& Measurements, 1987

17. Oksanen PJ: Estimated individual annual cosmic radiation doses for flight crews. Aviat Space Environ Med 69:621625,1998

18. Rampersaud YR, Foley KT, Shen AC, Williams S, Solomito M: Radiation exposure to the spine surgeon during fluoroscopically assisted pedicle screw insertion. Spine (Phila Pa 1976) 25:2637-2645, 2000

19. Rosenthal LS, Mahesh M, Beck TJ, Saul JP, Miller JM, Kay $\mathrm{N}$, et al: Predictors of fluoroscopy time and estimated radiation exposure during radiofrequency catheter ablation procedures. Am J Cardiol 82:451-458, 1998

20. Synowitz M, Kiwit J: Surgeon's radiation exposure during percutaneous vertebroplasty. J Neurosurg Spine 4:106-109, 2006

21. Tenenbaum S, Arzi H, Herman A, Friedlander A, Levinkopf M, Arnold PM, et al: Percutaneous posterolateral transfo- raminal endoscopic discectomy: clinical outcome, complications, and learning curve evaluation. Surg Technol Int 21:278-283, 2011

22. U1 Haque M, Shufflebarger HL, O'Brien M, Macagno A: Radiation exposure during pedicle screw placement in adolescent idiopathic scoliosis: is fluoroscopy safe? Spine (Phila Pa 1976) 31:2516-2520, 2006

23. Wang H, Huang B, Li C, Zhang Z, Wang J, Zheng W, et al: Learning curve for percutaneous endoscopic lumbar discectomy depending on the surgeon's training level of minimally invasive spine surgery. Clin Neurol Neurosurg 115:19871991, 2013

\section{Disclosures}

Dr. Iprenburg has received payments from joimax $\mathrm{GMbH}$ for teaching.

\section{Author Contributions}

Conception and design: all authors. Acquisition of data: Iprenburg, Godschalx. Analysis and interpretation of data: all authors. Drafting the article: all authors. Critically revising the article: all authors. Reviewed submitted version of manuscript: all authors. Approved the final version of the manuscript on behalf of all authors: Telfeian. Statistical analysis: all authors. Administrative/ technical/material support: Telfeian, Wagner, Godschalx. Study supervision: Iprenburg, Wagner, Godschalx.

\section{Correspondence}

Albert Telfeian, Department of Neurosurgery, Rhode Island Hospital, 593 Eddy St., Providence, RI 02903. email: atelfeian@ lifespan.org. 